\title{
Sex-specific associations between cerebrovascular blood pressure autoregulation and cardiopulmonary injury in neonatal encephalopathy and therapeutic hypothermia
}

\author{
Raul Chavez-Valdez ${ }^{1,2}$, Matthew O'Connor', Jamie Perin ${ }^{3}$, Michael Reyes ${ }^{4}$, Jillian Armstrong ${ }^{4}$, Charlamaine Parkinson ${ }^{2}$, \\ Maureen Gilmore', Jacky Jennings ${ }^{3}$, Frances J. Northington ${ }^{1,2}$ and Jennifer K. Lee ${ }^{2,4}$
}

BACKGROUND: Cardiopulmonary injury is common in neonatal encephalopathy, but the link with cerebrovascular dysfunction is unknown. We hypothesized that alterations of cerebral autoregulation are associated with cardiopulmonary injury in neonates treated with therapeutic hypothermia ( $\mathrm{TH})$ for neonatal encephalopathy.

METHODS: The cerebral hemoglobin volume index $(\mathrm{HV} x)$ from near-infrared spectroscopy was used to identify the mean arterial blood pressure (MAP) with optimal autoregulatory vasoreactivity $\left(\mathrm{MAP}_{\mathrm{OPT}}\right)$. We measured associations between MAP relative to $M A P_{\text {OPT }}$ and indicators of cardiopulmonary injury (duration of mechanical respiratory support and administration of inhaled nitric oxide (iNO), milrinone, or steroids).

RESULTS: We identified associations between cerebrovascular autoregulation and cardiopulmonary injury that were often sex-specific. Greater MAP deviation above MAP ${ }_{\text {OPT }}$ was associated with shorter duration of intubation in boys but longer ventilatory support in girls. Greater MAP deviation below $M_{\text {APT }}$ related to longer intensive care stay in boys. Milrinone was associated with greater MAP deviation below MAP ${ }_{\text {OPT }}$ in girls.

CONCLUSION: MAP deviation from MAP $_{\text {OPT }}$ may relate to cardiopulmonary injury after neonatal encephalopathy, and sex may modulate this relationship. Whereas MAP above MAP may protect the brain and lungs in boys, it may be related to cardiopulmonary injury in girls. Future studies are needed to characterize the role of sex in these associations.

Ninas eonatal encephalopathy affects $\sim 3$ in 1,000 births in the United States $(1,2)$. Neonatal encephalopathy causes multiorgan disease that includes cardiopulmonary injury in $80 \%$ of cases despite the use of therapeutic hypothermia (TH) $(1,3,4)$. Supporting cerebral autoregulation, the physiologic mechanism that maintains stable cerebral blood flow across a range of blood pressure, may protect the postischemic neonatal brain (5-8). Dysfunctional cerebral autoregulation is linked to pulmonary injury during hypothermic cardiopulmonary bypass (9) and longer duration of postoperative mechanical ventilation in adults (10). Whether strategies that support cerebral autoregulation also protect the cardiopulmonary system in neonates with neonatal encephalopathy is unknown.

The hemoglobin volume index ( $\mathrm{HVx})$ measures cerebral autoregulatory vasoreactivity using near infrared spectroscopy (NIRS). HVx is calculated by a continuous, moving correlation coefficient between mean arterial pressure (MAP) and the NIRS relative total tissue hemoglobin (rTHb), a surrogate measure of cerebral blood volume $(11,12)$. Because the $\mathrm{rTHb}$ optical density is calculated as the sum of oxygenated and deoxygenated hemoglobin (12), changes in tissue oxygen supply and metabolic rate during $\mathrm{TH}$ and mechanical ventilation affect HVx less than indices solely derived from oxyhemoglobin. HVx can be used to identify the range of MAP with most robust autoregulatory vasoreactivity-the optimal mean arterial blood pressure $\left(\mathrm{MAP}_{\mathrm{OPT}}\right)$ - after neonatal encephalopathy $(5,7,13)$. Blood pressure deviation below MAP $_{\mathrm{OPT}}$ after neonatal encephalopathy is linked to greater brain injury on magnetic resonance imaging (MRI) at $2 \mathrm{wk}(5,7)$ and worse neurocognitive outcomes at $2 \mathrm{y}(14)$.

Here, we investigated whether blood pressure deviation from $\mathrm{MAP}_{\mathrm{OPT}}$ is associated with cardiopulmonary injury after neonatal encephalopathy and TH. Our objective was to study the associations between deviation from $\mathrm{MAP}_{\mathrm{OPT}}$ and durations of cardiopulmonary support and stay in the neonatal intensive care unit (NICU). We analyzed all neonates and stratified the data by sex based on increasing evidence that responses to neonatal encephalopathy are sex-specific (15-20).

\section{METHODS}

The Johns Hopkins University (JHU) Institutional Review Board (IRB) approved this study. Between September 2010 and July 2015, neonates admitted to the NICU for neonatal encephalopathy were screened using criteria reported previously $(5,7,14)$. Criteria for neonatal encephalopathy requiring $\mathrm{TH}$ were based on the NICHD Neonatal Research Network's clinical trial (21). We obtained written

'Division of Neonatology, Department of Pediatrics, Johns Hopkins School of Medicine, Baltimore, Maryland; ${ }^{2}$ Neurosciences Intensive Care Nursery, Johns Hopkins School of Medicine, Baltimore, Maryland; ${ }^{3}$ Department of Pediatrics, Center for Child and Community Health Research (CCHR), Johns Hopkins School of Medicine, Baltimore, Maryland; ${ }^{4}$ Department of Anesthesiology and Critical Care Medicine, Johns Hopkins School of Medicine, Baltimore, Maryland. Correspondence: Raul Chavez-Valdez (rchavez2@jhmi.edu) Received 27 June 2016; accepted 2 January 2017; advance online publication 1 March 2017. doi:10.1038/pr.2017.23 
informed consent from parents of participants until May 2013. After that, NIRS monitoring became standard of care for neonatal encephalopathy at JHU NICU, and the IRB waived the requirement for written consent.

\section{Clinical Care}

The JHU NICU whole-body TH protocol was followed as previously published $(5,7,14)$. The treating team was blinded to HVx and made all clinical decisions. For persistent pulmonary hypertension of the newborn (PPHN), the primary mode of ventilation was highfrequency oscillatory ventilation. Clinicians initiated inhaled nitric oxide (iNO) (INOmax, Mallinckrodt pharmaceuticals, St Louis, MO) by endotracheal tube for the clinical diagnosis of PPHN based on persistently low $\mathrm{PaO}_{2}$ and oxygenation index $>20$ despite a $\mathrm{FiO}$ of 1.0 and lung recruitment strategies. PPHN was confirmed by echocardiogram. Per clinical protocol, iNO was started at $20 \mathrm{ppm}$ and weaned down once the goal $\mathrm{PaO}_{2}$ was sustained with $\mathrm{FiO} \leq$ 0.60. Dopamine was the first-line inotropic agent (maximum dose $20 \mathrm{mcg} / \mathrm{kg} / \mathrm{min}$ ), and clinicians determined the neonates' hemodynamic goals. Milrinone infusion was used for ventricular dysfunction diagnosed by echocardiogram and as part of PPHN management. All neonates received morphine intravenously (IV) per NICU TH protocol. Some neonates also received benzodiazepines or additional opiates. Occasionally clonidine was administered for shivering, and vecuronium was given for neuromuscular blockade when needed. Early hydrocortisone $\left(20 \mathrm{mg} / \mathrm{m}^{2} /\right.$ day IV) was used for arterial hypotension refractory to inotropes and/or adrenal insufficiency. Steroids were therefore considered a marker of severe systemic illness affecting multiple organ systems.

\section{Autoregulation Monitoring}

Our autoregulation monitoring methodology was previously published $(5,7,14)$. Briefly, neonatal cerebral oximetry probes were placed bilaterally on the forehead and connected to an INVOS 5100 NIRS machine (INVOS; Medtronic, Minneapolis, MN). Synchronous measurements of NIRS and arterial blood pressure signals at $100 \mathrm{~Hz}$ were processed with ICM+ software (Cambridge Enterprises, Cambridge, $\mathrm{UK})$. We analyzed time-integrated, 10-s means of MAP and $\mathrm{rTHb}$, a surrogate measure of cerebral blood volume, to filter out highfrequency waves from respiration and pulse. HVx is calculated by a continuous, moving Pearson correlation coefficient between MAP and rTHb from consecutive 10-s windows, and the average from each $300-s$ epoch is used to calculate one HVx value $(11,12)$. HVx is a continuous variable that ranges from -1 to +1 . When autoregulatory vasoreactivity is functional, HVx is negative or near-zero. A positive HVx that approaches 1 indicates dysfunctional autoregulatory vasoreactivity. Artifacts in the NIRS and MAP signals were manually filtered out, and data that comprised $<1 \%$ of the recording were removed as an additional method to remove artifacts $(5,7,14)$. After ruling out unilateral intracranial lesions on MRI, right and left $\mathrm{HVx}$ values were averaged and sorted into $5-\mathrm{mmHg}$ bins. The most negative $\mathrm{HVx}$ (nadir) was used to identify the MAP ${ }_{\mathrm{OPT}}$ with optimal autoregulatory vasoreactivity in each observation period $(\mathrm{TH}$, rewarming, and first $6 \mathrm{~h}$ of normothermia) $(5,7,13,14)$. Some neonates were coded as "unidentifiable $\mathrm{MAP}_{\mathrm{OPT}}$ " if a clear nadir could not be identified (14). An investigator (J.K.L.) blinded to outcome measures identified the MAP ${ }_{\mathrm{OPT}}$ values, which were corroborated by additional investigators (F.J.N. and M.G.). We calculated an area under the curve (AUC) below $\mathrm{MAP}_{\mathrm{OPT}}$ to combine the extent of blood pressure deviation with the amount of time spent with blood pressure below $\mathrm{MAP}_{\mathrm{OPT}}$ The AUC $(\mathrm{min} \bullet \mathrm{mmHg} / \mathrm{h})$ was calculated as time (minutes) spent with blood pressure below $\mathrm{MAP}_{\mathrm{OPT}}$ and blood pressure deviation $\left(\mathrm{mmHg}\right.$ ) below $\mathrm{MAP}_{\mathrm{OPT}}$, and then normalized for the duration of monitoring (hours) $(5,7,13,14)$. In summary, the parameters derived from $\mathrm{MAP}_{\mathrm{OPT}}$ in each period were: (i) maximal blood pressure deviation below or above MAP ; (ii) duration of time spent with blood pressure below, at, or above MAP as a percentage of the monitoring period; and (iii) AUC.

\section{Demographic and Perinatal Data}

Clinical data were retrieved from electronic medical record by investigators blinded to the autoregulation data (RC-V and MOC) (Table 1) (22)

\section{Markers of Cardiopulmonary Injury}

The duration of invasive mechanical ventilation, pressure support, and oxygen support were defined as the number of days with an endotracheal tube, with any support other than low-flow nasal cannula, and $\mathrm{FiO}_{2}>0.21$, respectively. $\mathrm{PaCO}_{2}$ measurements classified neonates into those with (23): (i) $\mathrm{PaCO}_{2}$ levels $35-45 \mathrm{mmHg}$; (ii) some $<35$ but none $>45 \mathrm{mmHg}$; (iii) none $<35$ but some $>45 \mathrm{mmHg}$; and (iv) some $<35$ and some $>45 \mathrm{mmHg}$. Data were also collected on the presence of electrical seizures; use of iNO, inotropes, milrinone, benzodiazepines, or clonidine during HVx monitoring; and receipt of steroids.

\section{Statistical Analysis}

Analyses were conducted with SASv9.2 (SAS Institute, Cary, NC). We determined associations between the autoregulation parameters $\left(\mathrm{MAP}_{\mathrm{OPT}}\right.$ and blood pressure in relation to $\left.\mathrm{MAP}_{\mathrm{OPT}}\right)$ in all neonates and stratified by sex. Linear regression for the logarithmic transformation of the average number of days of NICU stay, invasive mechanical ventilation, pressure support, and oxygen support was used to find both the crude (unadjusted) (data not shown) and adjusted associations with the autoregulation parameters from each of three observation periods (TH, rewarming, and first $6 \mathrm{~h}$ of normothermia). These analyses were adjusted for $\mathrm{PaCO}_{2}$ category, seizures, and receipt of a vasopressor, benzodiazepine, clonidine, or steroids. Binary outcomes (milrinone, iNO, or steroids) were analyzed as longitudinal outcomes over time, by autoregulation parameters within the same observation period. We used logistic regression for these binary measurements with generalized estimating equations to control for each measurement (milrinone, iNO, or steroid use) within the same neonate (24). Temporal associations between autoregulation parameters and subsequent and preceding milrinone and iNO use were analyzed by logistic regression. The analysis of milrinone, iNO, and steroid use were controlled for presence of seizures, and the analysis of iNO and steroids were additionally adjusted for $\mathrm{PaCO}_{2}$ category during autoregulation monitoring.

\section{RESULTS}

We screened 122 newborns from 27 September 2010 to 27 July 2015. Forty-six neonates were ineligible for the study because of an unreliable arterial blood pressure tracing (16), parents' refusal to consent (9), death (5), transfer to the pediatric ICU for extracorporeal membrane oxygenation (ECMO) (6), technical difficulties (5), inadequate monitoring resources (3), coagulopathy (1), complex heart disease (1), and language barriers (1). In total, 75 neonates received HVx monitoring (Supplementary Table S1 online). These patients received continuous $\mathrm{HVx}$ monitoring for $45.8 \pm 20.6 \mathrm{~h}$ (mean $\pm \mathrm{SD}$ ) ( $n=31$ girls/44 boys) during TH, $6.4 \pm 2.3 \mathrm{~h}$ ( $n=26$ girls/39 boys) during rewarming, and $5.6 \pm 0.9 \mathrm{~h}$ ( $n=25$ girls/38 boys) during normothermia. Ten neonates did not have HVx monitoring during rewarming because of ECMO (5), withdrawal of care (3), and technical difficulties (2). Two additional neonates did not have HVx monitoring during normothermia due to removal of the arterial catheter (1) or NIRS (1). Fifty-two neonates received vasopressors: 63\% (33/52; 21 boys and 12 girls) received dopamine only, 28\% (15/52; 7 boys and 8 girls) received dopamine and dobutamine, and $9 \%$ (5/52; 2 boys and 3 girls) received dopamine, dobutamine, and epinephrine.

We identified $\mathrm{MAP}_{\mathrm{OPT}}$ in 65 infants (87\%) during $\mathrm{TH}$ $\left(\mathrm{MAP}_{\mathrm{OPT}}=45 \pm 7.5 \mathrm{mmHg}\right)$; in 58 infants (89\%) during rewarming $\left(\mathrm{MAP}_{\mathrm{OPT}}=50 \pm 7.5 \mathrm{mmHg}\right)$; and in $60(95 \%)$ during normothermia $\left(\mathrm{MAP}_{\text {OPT }}=50 \pm 7.5 \mathrm{mmHg}\right)$. Clinical data about the infants with identified $\mathrm{MAP}_{\mathrm{OPT}}$ are presented in Table 1. Ten neonates (60\% boys) were excluded because their $\mathrm{MAP}_{\text {OPT }}$ could not be identified. Boys were heavier than 


\section{Autoregulation and cardiopulmonary injury $\quad$ Articles}

Table 1. Demographic and clinical characteristics of infants with an identified optimal mean arterial blood pressure

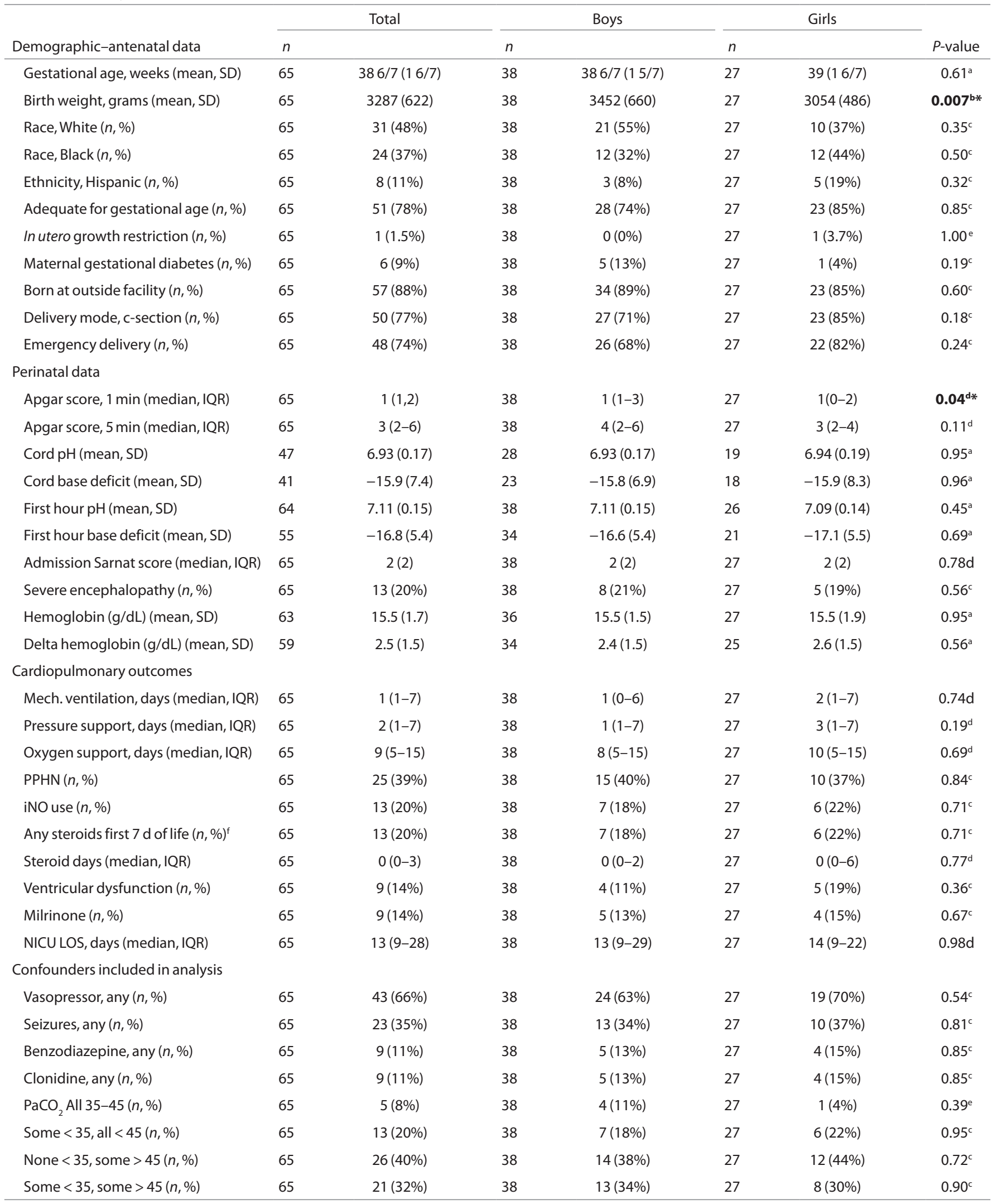

${ }^{*} P<0.05$ (boys vs. girls); ${ }^{a}$ unpaired $T$-test; ${ }^{b}$ unpaired $T$-test with Levene's test; ${ }^{\prime} x^{2}$ test; ${ }^{\mathrm{d}} \mathrm{Mann}$-Whitney $U$-test; ${ }^{e}$ Fisher's exact test; ${ }^{f}$ used either as outcome or confounder in modeling. iNO, inhaled nitric oxide; IQR, interquartile range; PPHN, persistent pulmonary hypertension of the newborn. 


\section{Articles | Chavez-Valdez et al.}

girls (mean $\pm \mathrm{SD}=3,452 \pm 660 \mathrm{~g}$ vs. $3,054 \pm 486 \mathrm{~g}, P=0.007$ ). Although the boys had higher 1-min Apgar scores than did girls $(P=0.04)$, the median 1 -min Apgar score was 1 for both sexes (Table 1). MAP and $\mathrm{MAP}_{\mathrm{OPT}}$ were similar in both sexes in each of the observation periods (Figure 1 and Table 2). During normothermia, girls spent more time with blood pressure below $\mathrm{MAP}_{\mathrm{OPT}}(P=0.05)$ than did boys. Accordingly, girls spent less time with blood pressure at $\mathrm{MAP}_{\mathrm{OPT}}$ than did boys during normothermia $(P=0.02)$. (Table 2 and Figure 2 )

\section{Sex-specific Associations between Cerebral Autoregulation and Duration of Respiratory Support}

Greater maximal blood pressure deviation above $\mathrm{MAP}_{\mathrm{OPT}}$ during normothermia was associated with $13 \%$ shorter duration of mechanical ventilation (days) among boys $(\beta=-0.142, P$ $=0.018$ ) (Supplementary Table $\mathbf{S} 2$ online). In girls, however, more time spent with blood pressure above $\mathrm{MAP}_{\text {OPT }}$ during rewarming was associated with $3 \%$ more days of positive pressure support $(\beta=0.033, P=0.044)$. Greater AUC $(\beta=$ $-0.004, P=0.046)$ and greater duration with blood pressure below $\mathrm{MAP}_{\mathrm{OPT}}(\beta=-0.036, P=0.024)$ during rewarming were associated with 1 and $4 \%$ fewer days of positive pressure support in girls, respectively. (Supplementary Table S3 online). Greater AUC $(\beta=-0.003, P=0.007)$, longer duration with blood pressure below $\operatorname{MAP}_{\mathrm{OPT}}(\beta=-0.022, P=0.005)$, and greater maximal blood pressure deviation below $\mathrm{MAPT}_{\mathrm{OPT}}(\beta=-0.081, P$ $=0.019$ ) during normothermia were also associated with fewer days of oxygen support in girls (Supplementary Table S4 online).

\section{Blood Pressure Below MAP ${ }_{\text {OPT }}$ is Associated with Length of NICU Stay}

The median duration of NICU stay was $13 \mathrm{~d}$ (IQR: 9, 28) and was similar between boys and girls (Table 1). Among boys, more time spent with blood pressure above $\mathrm{MAP}_{\mathrm{OPT}}$ during rewarming and normothermia $(\beta=-0.008$ for both, $P=0.016$
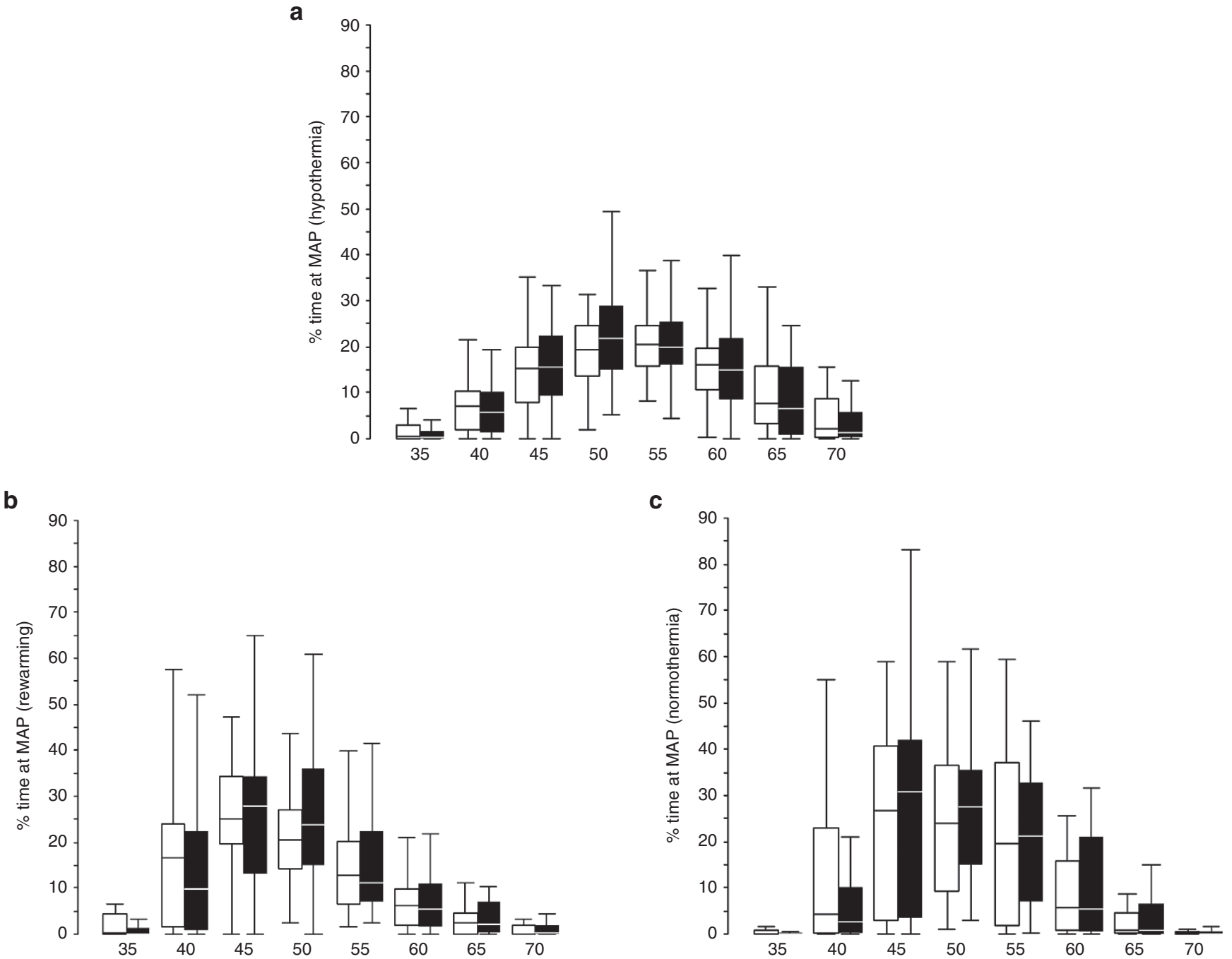

Figure 1. Box and whisker plots of the percentage of time that girls (white boxes) and boys (black boxes) spent at each level of mean arterial blood pressure (MAP, mmHg). The observation periods were therapeutic hypothermia (a, girls $(n=31)$, and boys $(n=44))$, rewarming (b, girls $(n=26)$, and boys $(n$ $=39)$ ), and the first $6 \mathrm{~h}$ of normothermia (c, girls $(n=25)$, and boys $(n=38)$ ). Box and whiskers plots, boxes represent the interquartile range (IQR) limited by the $25^{\text {th }}$ and $75^{\text {th }}$ percentile (lower and upper limit, respectively), line inside the box indicates the median and whiskers extend up the last datapoint within 1.5 times the IQR from the median. Outliers are not represented. 
Table 2. Optimal MAP $\left(\mathrm{MAP}_{\mathrm{OPT}}\right)$ and blood pressure parameters in relation to $\mathrm{MAP}_{\mathrm{OPT}}$

\begin{tabular}{|c|c|c|c|c|c|c|c|}
\hline \multirow[t]{2}{*}{ Parameter } & \multicolumn{3}{|c|}{ Total } & \multicolumn{2}{|l|}{ Boys } & Girls & \multirow[t]{2}{*}{$P$-value } \\
\hline & $n$ & Median (IQR) & $n$ & Median (IQR) & $n$ & Median (IQR) & \\
\hline \multicolumn{8}{|l|}{$\mathrm{MAP}_{\mathrm{OPT}}(\mathrm{mmHg})$} \\
\hline Rewarming & 58 & $50(45-55)$ & 33 & $50(45-55)$ & 25 & $50(45-58)$ & 0.91 \\
\hline Normothermia & 60 & $50(45-55)$ & 38 & $50(45-55)$ & 22 & $55(44-60)$ & 0.23 \\
\hline Rewarming & 58 & $180.3(21.5-474.8)$ & 33 & $175.5(24.8-386)$ & 25 & $197.9(8.9-556)$ & 0.59 \\
\hline Normothermia & 60 & $102.7(3-482.7)$ & 38 & $59(1-296)$ & 22 & $452(8.1-585)$ & 0.07 \\
\hline \multicolumn{8}{|c|}{ Duration of $\mathrm{BP}$ below $\mathrm{MAP}_{\mathrm{OPT}}$ (\% of the autoregulation monitoring period) } \\
\hline Hypothermia & 65 & $6(0.05-45.8)$ & 38 & $13.4(0-45.4)$ & 27 & $4.5(0.6-54.2)$ & 0.48 \\
\hline Hypothermia & 65 & $10.5(4.5-22.5)$ & 38 & $12.6(4.3-26)$ & 27 & $9.5(94.8-18.8)$ & 0.78 \\
\hline Rewarming & 58 & $12.5(3.6-30.8)$ & 33 & $12(3.6-32.2)$ & 25 & $13(3.9-25.8)$ & 0.59 \\
\hline Normothermia & 60 & $10(2.6-30.6)$ & 38 & $19.9(3.5-33.6)$ & 22 & $4.6(1.6-16.6)$ & $0.02 *$ \\
\hline \multicolumn{8}{|c|}{ Duration of $\mathrm{BP}$ above $\mathrm{MAP}_{\mathrm{OPT}}(\%$ of the autoregulation monitoring period) } \\
\hline Hypothermia & 65 & $73.6(25.8-94.3)$ & 38 & $63.7(31.8-94.6)$ & 27 & $79.2(20.7-93.8)$ & 0.88 \\
\hline Rewarming & 58 & $23.5(5.4-62)$ & 33 & $22.4(5.8-62.4)$ & 25 & $29(3.7-61.7)$ & 0.89 \\
\hline Normothermia & 60 & $26.7(0.9-84)$ & 38 & $35.3(2.7-89.9)$ & 22 & $2.1(0-64)$ & 0.06 \\
\hline \multicolumn{8}{|c|}{ Maximal BP deviation below $\mathrm{MAP}_{\mathrm{OPT}}(\mathrm{mmHg})$} \\
\hline Hypothermia & 65 & $10(2.5-15)$ & 38 & $10(0-15)$ & 27 & $10(5-20)$ & 0.33 \\
\hline
\end{tabular}

* $P \leq 0.05$ (boys vs. girls); aMann-Whitney U-test.

BP, blood pressure: MAP, mean arterial pressure.

Bold font is used from those values that are statistically significant.

and 0.004, respectively) was associated with a shorter NICU stay. Greater AUC $(\beta=0.001, P=0.018)$, longer duration of blood pressure below $\mathrm{MAP}_{\text {OPT }}(\beta=0.007, P=0.004)$, and greater maximal blood pressure deviation below $\mathrm{MAP}_{\mathrm{OPT}}(\beta=$ $0.024, P=0.018$ ) during normothermia were associated with longer NICU stays in boys. In contrast, greater AUC $(\beta=$ $-0.001, P=0.036)$, longer duration of blood pressure below $\mathrm{MAP}_{\text {OPT }}(\beta=-0.006, P=0.012)$, and greater maximal blood pressure deviation below $\mathrm{MAP}_{\mathrm{OPT}}(\beta=-0.024, P=0.024)$ during normothermia were associated with shorter NICU stays in girls (Supplementary Table S5 online).

\section{Cerebral Blood Pressure Autoregulation may be Associated with Milrinone Use}

Nine neonates (14\%; 5 boys and 4 girls) received milrinone for ventricular dysfunction or PPHN (Table 1). Nine (12\%) received milrinone during TH, 6 (8\%) during rewarming, and
$4(5 \%)$ during the first $6 \mathrm{~h}$ of normothermia. Milrinone use was associated with the maximal blood pressure deviation below $\mathrm{MAP}_{\mathrm{OPT}}$ in the same time period in girls $(\beta=0.157 ; P=0.005)$; Supplementary Table S6 online). Longitudinal analysis of autoregulation and milrinone use in preceding or subsequent periods were not associated (data not shown).

\section{The Cerebral Autoregulation Parameters were not Associated with Clinical Use of iNO or Steroids}

Twenty-nine infants received iNO for clinical diagnoses of PPHN. Nineteen neonates received iNO during HVx monitoring (32\% of girls and $21 \%$ of boys, Supplementary Table S1 online), and 13 of these neonates had an identified MAP ${ }_{\text {OPT }}$ ( $22 \%$ of girls and $18 \%$ of boys, Table 1 ). The iNO was initiated at $20 \mathrm{ppm}$ (maximum dose) in all infants and weaned per clinical protocol. iNO was started within the first $24 \mathrm{~h}$ of life in $84 \%$ of neonates (16/19), between 24 and $48 \mathrm{~h}$ of life in 5\% (1/19), 
a

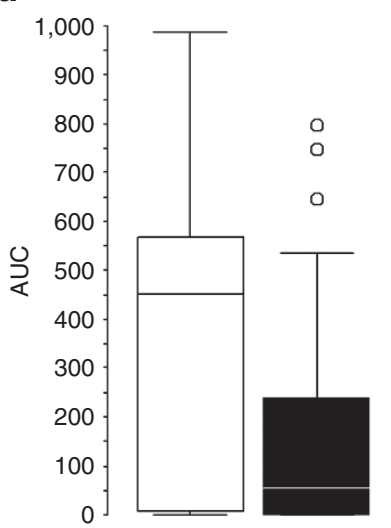

b

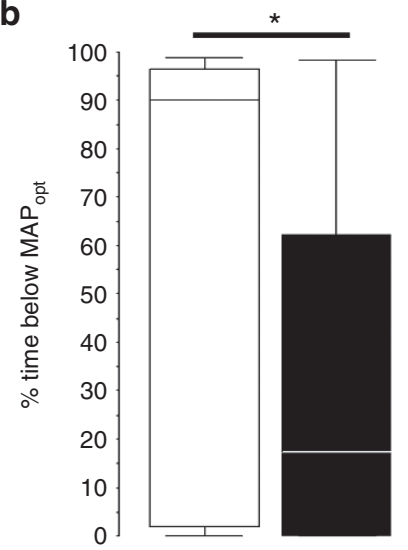

C

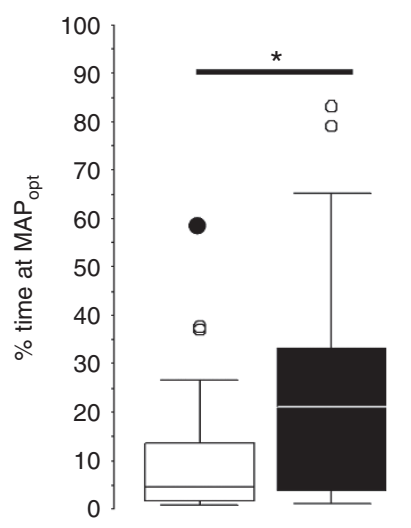

d

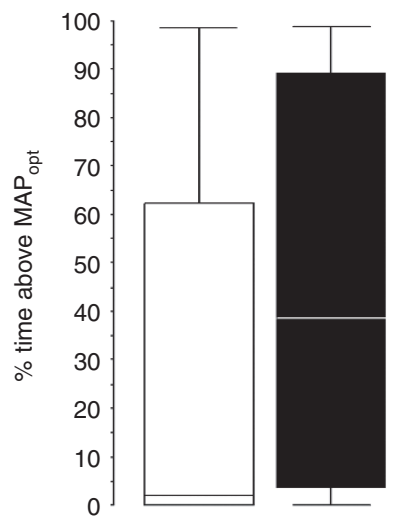

Figure 2. Box and whisker plots of the area under the curve (AUC) below mean arterial blood pressure (MAP) OPT $(\mathbf{a})$, and percent time spent below MAP $_{\mathrm{OPT}}$ (b), at $\mathrm{MAP}_{\mathrm{OPT}}(\mathbf{c})$, and above $\mathrm{MAP}_{\mathrm{OPT}}$ (d) for girls (white boxes) and boys (black boxes) during $6 \mathrm{~h}$ of normothermia (girls $n=22$, and boys $n=38$ ). Boxes represent the interquartile range (IQR) limited by the $25^{\text {th }}$ and $75^{\text {th }}$ percentile (lower and upper limit, respectively), line inside the box indicates the median and whiskers extend up the last datapoint within 1.5 times the IQR from the median. Outliers (open circles) are those datapoints within 1.5 to 3 times the IQR from the median and extremes (closed circles) are those datapoint beyond 3 times the IQR form the median. ${ }^{*} P<0.05$ (boys vs. girls). Analysis performed by Mann-Whitney U-Test.

and soon after rewarming in $11 \%(2 / 19)$. Among neonates who started iNO during $\mathrm{TH}, 88 \%(15 / 17)$ received iNO for at least the first $7 \mathrm{~d}$ of life, and the other $12 \%(2 / 17)$ were weaned off iNO before the end of TH. Thus, $23 \%$ of neonates undergoing $\mathrm{HVx}$ monitoring received iNO during $\mathrm{TH}$ and rewarming and $27 \%$ during normothermia. Blood pressure parameters in relation to $\mathrm{MAP}_{\mathrm{OPT}}$ were not associated with the simultaneous and clinical use of iNO for PPHN (Supplementary Table S6 online). Similarly, longitudinal analysis of autoregulation and iNO in preceding or subsequent periods were not associated (data not shown).

Girls and boys received steroids for a similar length of time. Twelve (16\%) neonates received steroids during TH, 15 (20\%) during rewarming, and $16(21 \%)$ during the first $6 \mathrm{~h}$ of normothermia. Thirteen infants (20\%; 6 girls and 7 boys) with an identified $\mathrm{MAP}_{\mathrm{OPT}}$ received steroids during the first $7 \mathrm{~d}$ of life (Table 1). Blood pressure in relation to $\mathrm{MAP}_{\mathrm{OPT}}$ was not associated with steroid use (Supplementary Table S6 online).

\section{DISCUSSION}

We investigated the association between cerebral autoregulatory vasoreactivity measured by $\mathrm{HVx}$ and cardiopulmonary outcomes in neonates treated with $\mathrm{TH}$ for neonatal encephalopathy. Although girls and boys had similar $\mathrm{MAP}_{\mathrm{OPT}}$ values, the relationships between blood pressure autoregulation and lung injury were often sex-specific. While blood pressure above $\mathrm{MAP}_{\mathrm{OPT}}$ during normothermia was associated with shorter duration of intubation in boys, it was associated with longer durations of intubated or noninvasive respiratory pressure support in girls. We previously demonstrated that blood pressure below $\mathrm{MAP}_{\mathrm{OPT}}$ is associated with more severe brain injury on MRI $(5,7)$ at $2 \mathrm{wk}$ and worse neurocognitive outcomes at $2 \mathrm{y}$ (14). Our current findings suggest that maintaining blood pressure above $\mathrm{MAP}_{\mathrm{OPT}}$ protects both the brain and lungs in boys but not in girls. Additionally, blood pressure deviation below $\mathrm{MAP}_{\mathrm{OPT}}$ during normothermia was associated with a longer NICU stay in boys but shorter stay in girls. These findings provide new evidence for sex differences in the relationships between cerebral autoregulation and cardiopulmonary injury following neonatal encephalopathy.

Even though boys and girls had similar MAP $_{\text {ОРT }}$ during $\mathrm{TH}$, rewarming, and the first $6 \mathrm{~h}$ of normothermia, girls had greater blood pressure deviation below $\mathrm{MAP}_{\mathrm{OPT}}$ than did boys during normothermia. Boys also spent more time with blood pressure at $\mathrm{MAP}_{\mathrm{OPT}}$ during normothermia, which indicates that boys had better autoregulatory function than girls in this pilot study cohort. The reasons behind this sex difference are not clear. We controlled for vasopressor use in the analysis given the confounding effects of vasopressors on autoregulation. Although MAP and thus time spent above MAP ${ }_{\mathrm{OPT}}$ are affected by vasopressor and inotropic medications, boys and girls with identified $\mathrm{MAP}_{\mathrm{OPT}}$ were treated in equal proportions with these agents ( $63 \%$ vs. $70 \%$, respectively, $P=0.54$ ). The type of vasopressor should be considered given potential sex-dependent differences in autoregulatory responses to different vasopressors. For example, phenylephrine and norepinephrine protect autoregulation only in female piglets with traumatic brain injury $(25,26)$, whereas dopamine preserves autoregulation in both sexes (27). In our study, vasopressor treatment was similar between boys and girls. Dopamine was universally used as the first-line agent, and dobutamine was added for boys and girls in equal proportions. The reciprocal interactions between cerebral and cardiopulmonary injuries are not well studied in neonatal encephalopathy, and the influence of different vasopressors on this complex relationship deserves further study.

The relationships between cerebral autoregulation and cardiopulmonary outcomes were often sex-specific. In boys, higher blood pressure above $\mathrm{MAP}_{\mathrm{OPT}}$ was associated with fewer days of intubation, and each $1 \mathrm{mmHg}$ increase in maximal MAP above $\mathrm{MAP}_{\mathrm{OPT}}$ during normothermia was associated 
with a $13 \%$ decrease in days of intubation. In contrast, more time with blood pressure above $\mathrm{MAP}_{\mathrm{OPT}}$ during rewarming related to longer periods of intubation or noninvasive mechanical ventilation in girls. More blood pressure deviation below $\mathrm{MAP}_{\mathrm{OPT}}$ during normothermia corresponded to fewer days of supplemental oxygen in girls but not boys. Blood pressure deviation below $\mathrm{MAP}_{\mathrm{OPT}}$ is associated with more severe brain injury on MRI at $2 \mathrm{wk}(5,7)$ and worse neurocognitive outcomes at 2 y (14) in neonatal encephalopathy. Hence, it appears that maintaining blood pressure at or above $\mathrm{MAP}_{\mathrm{OPT}}$ in boys may protect both the brain and lungs, whereas blood pressure above $\mathrm{MAP}_{\text {OPT }}$ could worsen pulmonary injury and prolong the need for respiratory support in girls. Raising MAP to support cerebral perfusion pressure may cause cardiogenic strain with pulmonary edema or lung injury as previously reported in a preclinical model of neonatal hypoxia-ischemia (28). However, it is unclear why girls might be more susceptible to these mechanisms than boys.

Blood pressure in relation to $\mathrm{MAP}_{\mathrm{OPT}}$ did not affect the likelihood of receiving iNO for PPHN or ventricular dysfunction. While it is possible that cerebral delivery of nitrite from iNO (29) may cause cerebral vasodilation (30), iNO did not affect $\mathrm{MAP}_{\mathrm{OPT}}$ or increase blood pressure deviation below $\mathrm{MAP}_{\mathrm{OPT}}$ during clinical use for PPHN in our cohort. The iNO dosing by endotracheal tube was determined by cardiopulmonary clinical indications rather than for potential cerebral vasodilation. Milrinone may decrease systemic blood pressure or dilate the cerebral vasculature (31). In this pilot study, milrinone use was associated with greater maximal decrease in blood pressure below $\mathrm{MAP}_{\mathrm{OPT}}$ among girls. Further studies are needed to determine the influence of milrinone on cerebral blood pressure autoregulation.

Our prior research in neonatal encephalopathy identified important relationships between autoregulation during $\mathrm{TH}$ and rewarming and neurologic outcomes $(5,7,14)$. In this study, we identified several significant associations between the cardiopulmonary outcomes and blood pressure in relation to $\mathrm{MAP}_{\mathrm{OPT}}$ during rewarming and normothermia. Many of these relationships were observed solely in one sex but not the other. The absence of associations during hypothermia may be related to our methods of examining blood pressure in relation to $\mathrm{MAP}_{\mathrm{OPT}}$ during the entire hypothermic period which, while permitting direct comparisons between hypothermia, rewarming and normothermia, may sacrifice some granularity in the data across time.

Our study had several limitations. A causal relationship between blood pressure autoregulation and cardiopulmonary outcomes cannot be determined with the current design. Selection bias may have led to inclusion of less-ill neonates because parents of the sickest babies and those deemed likely to die were not consented for the study during the initial period of data collection, and HVx was not monitored in neonates who died, were withdrawn from life-sustaining treatments, or were transferred for possible ECMO. Larger studies are required to further define the multifactorial nature of the complex interactions between cerebral autoregulation and the cardiopulmonary system. Our observational data suggest that sex may play a role in this relationship. We did not measure HVx during the first $24 \mathrm{~h}$ of life in many neonates, and we did not evaluate the trajectory of $\mathrm{MAP}_{\mathrm{OPT}}$ across time in short epochs. Lastly, we acknowledge that multiple testing of outcome data derived from single patients may introduce statistical limitations in the interpretation of the results.

In conclusion, we report the potential use of cerebral autoregulation monitoring with $\mathrm{HVx}$ to identify blood pressures that support cerebral and cardiopulmonary recovery during and after TH for neonatal neonatal encephalopathy. $\mathrm{MAP}_{\mathrm{OPT}}$ measurements from HVx may provide information about the risk of lung injury, and sex may modulate cerebral vascular-pulmonary interactions to some degree in neonatal encephalopathy. Maintaining blood pressure above $\mathrm{MAP}_{\mathrm{OPT}}$ may protect both the brain and lungs in boys, but it is associated with respiratory compromise in girls. Girls who receive milrinone may also be more likely to have blood pressure deviation below $\mathrm{MAP}_{\mathrm{OPT}}$. Growing preclinical and clinical data suggest sexdimorphism in physiological responses to neonatal HI injury. Understanding these potentially divergent injury mechanisms in relation to autoregulation would improve treatment strategies in neonatal encephalopathy. Furthermore, our results support the need for large, prospective studies that are powered to evaluate sex-differences in pathophysiologic responses to neonatal encephalopathy as well as the interactions between neurologic and non-neurologic systems in neonates.

\section{SUPPLEMENTARY MATERIAL}

Supplementary material is linked to the online version of the paper at http:// www.nature.com/pr

\section{ACKNOWLEDGMENTS.}

We are grateful to the Johns Hopkins Hospital nursing staff for their constant support.

\section{STATEMENT OF FINANCIAL SUPPORT}

This study is supported by National Institutes of Health (Bethesda, MD) R01HD070996 (F.J.N.), R01HD074593 (F.J.N.), K08NS080984 (J.K.L.), and R21HD072845 (J.K.L.), by Johns Hopkins University (Baltimore, MD) Clinician Scientist Award (J.K.L.), by the American Heart Association (Dallas, TX) Grantin-Aid (J.K.L.), and the Sutland-Pakula Endowment for Neonatal Research (RC-V). Medtronic (Minneapolis, MN) provided partial funding for this study, but had no involvement in study design, analysis, interpretation and writing of this manuscript.

Disclosure: The authors declare no financial ties to products in the study or conflicts of interest.

\section{REFERENCES}

1. Graham EM, Ruis KA, Hartman AL, Northington FJ, Fox HE. A systematic review of the role of intrapartum hypoxia-ischemia in the causation of neonatal encephalopathy. Am J Obstet Gynecol 2008;199:587-95.

2. Dammann O, Ferriero D, Gressens P. Neonatal encephalopathy or hypoxicischemic encephalopathy? Appropriate terminology matters. Pediatr Res 2011;70:1-2.

3. Hankins GD, Koen S, Gei AF, Lopez SM, Van Hook JW, Anderson GD. Neonatal organ system injury in acute birth asphyxia sufficient to result in neonatal encephalopathy. Obstet Gynecol 2002;99(5 Pt 1):688-91.

4. Shankaran S, Barnes PD, Hintz SR, et al.; Eunice Kennedy Shriver National Institute of Child Health and Human Development Neonatal Research Network. Brain injury following trial of hypothermia for neonatal hypoxic-ischaemic encephalopathy. Arch Dis Child Fetal Neonatal Ed 2012;97:F398-404. 
5. Howlett JA, Northington FJ, Gilmore MM, et al. Cerebrovascular autoregulation and neurologic injury in neonatal hypoxic-ischemic encephalopathy. Pediatr Res 2013;74:525-35.

6. Massaro AN, Govindan RB, Vezina G, et al. Impaired cerebral autoregulation and brain injury in newborns with hypoxic-ischemic encephalopathy treated with hypothermia. J Neurophysiol 2015;114:818-24.

7. Tekes A, Poretti A, Scheurkogel MM, et al. Apparent diffusion coefficient scalars correlate with near-infrared spectroscopy markers of cerebrovascular autoregulation in neonates cooled for perinatal hypoxic-ischemic injury. AJNR Am J Neuroradiol 2015;36:188-93.

8. Chalak LF, Tian F, Tarumi T, Zhang R. Cerebral hemodynamics in asphyxiated newborns undergoing hypothermia therapy: pilot findings using a multiple-time-scale analysis. Pediatr Neurol 2016;55:30-6.

9. Ono M, Joshi B, Brady K, et al. Risks for impaired cerebral autoregulation during cardiopulmonary bypass and postoperative stroke. $\mathrm{Br} \mathrm{J}$ Anaesth 2012;109:391-8.

10. Ono M, Brady K, Easley RB, et al. Duration and magnitude of blood pressure below cerebral autoregulation threshold during cardiopulmonary bypass is associated with major morbidity and operative mortality. J Thorac Cardiovasc Surg 2014;147:483-9.

11. Larson AC, Jamrogowicz JL, Kulikowicz E, et al. Cerebrovascular autoregulation after rewarming from hypothermia in a neonatal swine model of asphyxic brain injury. J Appl Physiol (1985) 2013;115:1433-42.

12. Lee JK, Kibler KK, Benni PB, et al. Cerebrovascular reactivity measured by near-infrared spectroscopy. Stroke 2009;40:1820-6.

13. Lee JK, Brady KM, Chung SE, et al. A pilot study of cerebrovascular reactivity autoregulation after pediatric cardiac arrest. Resuscitation 2014;85:1387-93.

14. Burton VJ, Gerner G, Cristofalo E, et al. A pilot cohort study of cerebral autoregulation and 2-year neurodevelopmental outcomes in neonates with hypoxic-ischemic encephalopathy who received therapeutic hypothermia. BMC Neurol 2015;15:209.

15. Ahnstedt H, Mostajeran M, Blixt FW, et al. U0126 attenuates cerebral vasoconstriction and improves long-term neurologic outcome after stroke in female rats. J Cereb Blood Flow Metab 2015;35:454-60.

16. Breu M, Zhang J, Porambo M, et al. Diffusion tensor imaging abnormalities in the cerebral white matter correlate with sex-dependent neurobehavioral deficits in adult mice with neonatal ischemia. Dev Neurosci 2016;38:83-95.

17. Chavez-Valdez R, Martin LJ, Razdan S, Gauda EB, Northington FJ. Sexual dimorphism in BDNF signaling after neonatal hypoxia-ischemia and treatment with necrostatin-1. Neuroscience 2014;260:106-19.

18. Jia J, Davis CM, Zhang W, et al. Sex- and isoform-specific mechanism of neuroprotection by transgenic expression of P450 epoxygenase in vascular endothelium. Exp Neurol 2016;279:75-85.
19. Milerová M, Drahota Z, Chytilová A, Tauchmannová K, Houštěk J, Oštádal B. Sex difference in the sensitivity of cardiac mitochondrial permeability transition pore to calcium load. Mol Cell Biochem 2016;412:147-54.

20. Xue Q, Xiao D, Zhang L. Estrogen regulates angiotensin II receptor expression patterns and protects the heart from ischemic injury in female rats. Biol Reprod 2015;93:6.

21. Shankaran S, Laptook AR, Ehrenkranz RA, et al.; National Institute of Child Health and Human Development Neonatal Research Network. Whole-body hypothermia for neonates with hypoxic-ischemic encephalopathy. N Engl J Med 2005;353:1574-84.

22. Sarnat HB, Sarnat MS. Neonatal encephalopathy following fetal distress. A clinical and electroencephalographic study. Arch Neurol 1976;33:696-705.

23. Pappas A, Shankaran S, Laptook AR, et al.; Eunice Kennedy Shriver National Institute of Child Health and Human Development Neonatal Research Network. Hypocarbia and adverse outcome in neonatal hypoxicischemic encephalopathy. J Pediatr 2011;158:752-758.e1.

24. Zeger SL, Liang KY. Longitudinal data analysis for discrete and continuous outcomes. Biometrics 1986;42:121-30.

25. Armstead WM, Kiessling JW, Riley J, Kofke WA, Vavilala MS. Phenylephrine infusion prevents impairment of ATP- and calcium-sensitive potassium channel-mediated cerebrovasodilation after brain injury in female, but aggravates impairment in male, piglets through modulation of ERK MAPK upregulation. J Neurotrauma 2011;28:105-11.

26. Armstead WM, Riley J, Vavilala MS. Preferential protection of cerebral autoregulation and reduction of hippocampal necrosis with norepinephrine after traumatic brain injury in female piglets. Pediatr Crit Care Med 2016;17:e130-7.

27. Armstead WM, Riley J, Vavilala MS. Dopamine prevents impairment of autoregulation after traumatic brain injury in the newborn pig through inhibition of Up-regulation of endothelin-1 and extracellular signal-regulated kinase mitogen-activated protein kinase. Pediatr Crit Care Med 2013;14:e103-11.

28. Arruza L, Pazos MR, Mohammed N, et al. Hypoxic-ischemic brain damage induces distant inflammatory lung injury in newborn piglets. Pediatr Res 2016;79:401-8.

29. Ibrahim YI, Ninnis JR, Hopper AO, et al. Inhaled nitric oxide therapy increases blood nitrite, nitrate, and s-nitrosohemoglobin concentrations in infants with pulmonary hypertension. J Pediatr 2012;160:245-51.

30. Truong GT, Schröder HJ, Liu T, et al. Role of nitrite in regulation of fetal cephalic circulation in sheep. J Physiol 2014;592:1785-94.

31. Nishiguchi M, Ono S, Iseda K, Manabe H, Hishikawa T, Date I. Effect of vasodilation by milrinone, a phosphodiesterase III inhibitor, on vasospastic arteries after a subarachnoid hemorrhage in vitro and in vivo: effectiveness of cisternal injection of milrinone. Neurosurgery 2010;66:158-64; discussion 164. 